\title{
CORRECTION
}

\section{Correction to: Implementing Unplugged Coding Activities in Early Childhood Classrooms}

\author{
Joohi Lee ${ }^{1}\left(\mathbb{D} \cdot\right.$ Jo Junoh $^{2}$
}

Published online: 7 September 2019

๑) Springer Nature B.V. 2019

\section{Correction to: Early Childhood Education Journal https://doi.org/10.1007/s10643-019-00967-z}

The original version of this article unfortunately contained a typo in the co-author name.

The author name should be Jo Junoh instead it is published incorrectly as Jo Junho.

The original article has been corrected.

Publisher's Note Springer Nature remains neutral with regard to jurisdictional claims in published maps and institutional affiliations.

The original article can be found online at https://doi.org/10.1007/ s10643-019-00967-z.

Joohi Lee

joohilee@uta.edu

1 Early Childhood Mathematics Education, University of Texas at Arlington, Science Hall 322C, 502 Yates, Arlington, TX 76019, USA

2 Early Childhood Education, Pusan National University of Education, Pusan, Korea 